Maria A. Abramova, Dr. of Pedagogical Sciences, Professor Institute of Philosophy and Law of the Siberian Branch of the Russian Academy of Sciences (Novosibirsk, Russia) marika24@yandex.ru

\title{
CONSERVATION OF HISTORICAL AND CULTURAL HERITAGE LOCATED IN RUSSIAN REGIONS AS A CONDITION FOR HARMONIZATION OF INTER-ETHNIC RELATIONS
}

\author{
The reported study was funded by Russian Fund of Basic Research \\ according to the research project № 18-011-00223 \\ "Impact of Linguacultural Specifics on Youth's Attitudes in Inter-Ethnic Relations")
}

\begin{abstract}
The paper reviews some results of comparative analysis of theoretical foundations of state ethnical policy in Imperial, Soviet and post-Soviet Russia; the dependence between state decisions in "national question" and general atmosphere of inter-ethnic communication in the country is revealed. The author notes that in modern Russia, processes of a personality's ethnic self-identification often become an object for some manipulations on the part of actors interested in political destabilization of the country. Learning rich domestic historical and cultural heritage by Russian youth is considered by the author as a measure for strengthening inter-ethnic accord in multicultural Russia.

Key words: inter-ethnic communication, state ethnic policy, ethnic policy in the Russian Empire, ethnic policy in Soviet Russia, ethnic policy in post-Soviet Russia, a personality's ethnic identity, multiculturalism, multicultural society, ethnocentrism, historical and cultural heritage, a museum.
\end{abstract}

УДК 325:[281.96+316.343.43](571.15)

DOI: $10.32340 / 2414-9101-2019-2-77-81$

И. В. Куприянова, доктор исторических наук, доцент Алтайский государственный институт культуры (Барнаул, Россия) irinak-63@mail.ru

\section{ВЗАИМОДЕЙСТВИЕ РУССКИХ СТАРООБРЯДЦЕВ С АБОРИГЕНАМИ АЛТАЯ КАК КОЛОНИЗАЦИОННЫЙ РЕСУРС}

Аннотация. Рассмотрены формы сотрудничества русских старообрядцев с коренным населением в процессе хозяйственно-культурного освоения ими территории Горного Алтая в XIX - начале XX вв. Сложные природно-климатические условия, а также стремление к уединению и удалению от обитаемых мест и административных центров делали это взаимодействие почти единственным ресурсом выживания и адаптации старообрядцев. Одной из форм взаимодействия двух этнических групп являлось завязывание родственных связей, в которых взаимовосприятие культурной информации происходило ускоренными темпами. Результатом таких связей становилось вовлечение аборигенов в сферу русской православной цивилизации.

Ключевые слова: старообрядчество, русская колонизация Горного Алтая, взаимодействие с кочевниками, ассимиляиия, перекрещивание алтайщев, распространение земледельческой культуры, обновление генофонда.

Старообрядческие общества, представлявшие собой сравнительно небольшие по численности группы религиозных «отщепенцев», искавших подходящих условий для сохранения православного вероисповедания, проделали на территории Сибири колоссальную работу по первоначальному освоению ранее необжитых пространств, по-видимому, невозможную для других колонизационных этнокультурных и конфессиональных групп. В процессе ее выполнения старообрядческие коллективы проникали во многие, в том числе труднодоступные, безлюдные районы, осуществляя их вовлечение в экономику страны: по существу, выполняя работу государственного значения. Так, например, на Алтае старообрядцы, продвигаясь на южные рубежи сибирского пограничья, посредством основания населенных пунктов, распашки целинных почв, разведки экономических возможностей территорий закрепляли эти ценные земли в составе Российской империи: «воздвигали новые столбы русской границы» [1, с. 5].

Проникновение в необжитые территории, их первоначальное освоение и превращение в цветущие сибирские окраины - весьма трудоемкий процесс, требовавший громадных усилий, терпения и целеустремленности. Тем не менее, культурно-хозяйственное освоение старообрядческими коллективами отдельных местностей Сибири проходило довольно быстро. Не случайно старообрядцы, может 
быть, наряду только с некоторыми группами сектантов, рассматривались сибирской администрацией как «наиболее желательный колонизационный элемент» [2, с. 257]. Стремительно продвигалось дело колонизации Алтая: посетивший в 1771 г. селения «поляков» П. С. Паллас застал их относительно освоившимися всего через шесть-семь лет после водворения [3, с. 222]. Лучшими колонизаторами Алтая считал «поляков» также и Н. М. Ядринцев [4, с. 43].

Возникает вопрос: что послужило старообрядцам опорой в этих успешных колонизационных процессах? - безусловно, в числе основных причин можно назвать их чрезвычайно острую мотивированность в стремлении бежать из неблагоприятной, а то и прямо враждебной социальной среды и достичь желаемого уединения - убежища, в котором возможны безопасное существование, сохранение веры и воспроизводство религиозного культа.

Вместе с тем имели место и вполне осязаемые факторы: те материальные возможности, которые старообрядцы, как никто другой, умели находить и использовать для достижения своих целей. Одним из важнейших адаптационных ресурсов, в особенности для старообрядцев предгорной и горной зон, стало взаимодействие с аборигенами - алтайцами («калмыками») и казахами («киргизами»). В условиях безлюдья, суровой природы, часто не совместимой не только со здоровьем, но и с самой жизнью, кочевники - подвижное, перетекающее и весьма немногочисленное население, - были все же единственными человеческими коллективами, от которых можно было ожидать какой-то поддержки: получить информацию, нанять проводников, завязать меновую торговлю и др.

Нужно признать, что контакты староверов с народами Горного Алтая далеко не всегда строились на бесконфликтной основе. Нередко они развивались в обычном русле взаимоотношений русского новопришлого и тюркского коренного населения, в которых важную роль играло стремление первого к наживе за счёт второго, что выразилось, например, в неэквивалентной торговле, перехвате инициативы в наиболее доходных промыслах - ореховом и охотничьем, и особенно в присвоении инородческих земельных угодий.

Наибольшее количество конфликтов возникало именно из-за земли: местами они перерастали в настоящую ожесточённую борьбу «за землю, за долину, за пядь земли ... между инородческим и русским элементом» [5, с. 617]. Проникновение русской колонизации на территорию Горного Алтая официально запрещалось законами и распоряжениями местной администрации из-за опасения стеснения кочевников в угодьях, которое негативно отражалось на поступлении ясака в казну. Русская деревня имела раскидистую структуру, в которой много места занимало хозяйство, требовавшее обширных земельных участков. Усадьба, пашня, покос, пасека, водяная мельница, воскобойня, маральник и другие его компоненты могли в ряде случаев рассредоточиваться на территории в 200 гектар, так как крестьяне, не стеснённые земельной теснотой, выбирали для них наиболее удобные места. При этом они вторгались в земли коренного населения, тесня его своими, вновь возникавшими населенными пунктами - деревнями, пасеками, заимками, отвечая на жалобы аборигенов, что «это земля царская, то есть, наша».

При столкновении экономических интересов старообрядцы, не задумываясь, вступали с аборигенами в состояние конфронтации, не боясь доводить ее до вооруженных столкновений. Заняв какойлибо участок земли, пригодный для земледелия, кержаки удерживали его за собой, при необходимости защищая свои позиции всеми, доступными им, средствами, такими, как поджоги, разрушение поскотины, отравление или угон скота, опахивание и обсеивание юрт, даже избиение.

Со своей стороны, старообрядцы постоянно страдали от систематической баранты - отгона скота, преимущественно урянхайцами, которых Н. М. Ядринцев характеризовал как «замечательных воров и конокрадов». Иногда, в качестве компенсации за угнанных лошадей, кержаки отбирали такое же их количество у соседей-алтайцев, говоря: «Это то, что ваши братья у нас угнали, с них и получите».

Вместе с тем, является очевидным, что процессы взаимной ассимиляции протекали у староверов легче и проще всего именно с коренным населением. Традиционная культура старообрядцев Алтая содержит ряд заимствований у аборигенов, которые имели, как правило, утилитарное значение и не касались духовных основ культуры. В контактах с нерусским населением староверам не грозила опасность религиозно-культурного растворения, поскольку это было взаимодействие двух принципиально различных культур, в котором отсутствовал элемент духовной экспансии, что позволяло обеим сторонам сохранять свои базовые ценности.

В ситуациях, когда присутствие и жизнедеятельность представителей этих народов не противоречили их экономическим интересам, они стремились жить с ними в мире. В этой гибкой крестьянской дипломатии заключалась тайна русской колонизации, так как для крестьян-земледельцев невозможно было бы долго существовать во вражде с коренным населением: «Колонист-крестьянин являлся и основывал своё хозяйство в этих местах ... Ему нужен был мир безусловно ... Если бы рус- 
ский крестьянин и пионер брал только все напором, грубым вторжением, он не устоял бы здесь, окруженный враждебными условиями, его бы вытеснили» [6, с. 23-24].

Доказательством того, что старообрядцы с давних времён установили добрые отношения с «киргизами» и с «калмыками» (т. е. с казахами и алтайцами), является то обстоятельство, что они усвоили языки этих коренных народов. Среди бухтарминских каменщиков не редкостью было умение говорить по-китайски, по-монгольски, по-джунгарски, притом, что в Сибири русские обычно не утруждали себя освоением языков местных народов, вынуждая их самих учиться понимать и говорить по-русски.

Наиболее явным проявлением близости русских старообрядцев с аборигенами стало вовлечение ими алтайцев и казахов в свою хозяйственную жизнь. Так, например, бухтарминцы покупали и выменивали у казахов крупный рогатый скот и верховых лошадей, которых им же отдавали на выпас; выменивали у них на муку и меха такие товары, как седла и вся верховая сбруя, войлоки, овчины, шерсть, кошмы, арканы и пр. [7, с. 580] Ещё в 1920-х гг. кержаки нанимали казахов для переработки собственных материалов: битья шерсти, изготовления серебряных украшений для упряжи, шитья грубой рабочей одежды. Кроме того, практиковался наем казахов в сторожа на пасеки и в маральники, а примерно с середины XIX в. они начали поставлять кержакам Бухтармы рабочую силу для некоторых земледельческих работ, что стимулировало их освоение [7, с. 581; 8, с. 42-44]. Старообрядцы предгорий также нанимали в батраки местных кумандинцев; при этом этнокультурная и конфессиональная принадлежность наёмных работников интересовала их значительно меньше, чем качество их труда.

Уединённые местности в высокогорье, каковой, например, является Уймонская долина крупнейшая горная котловина Русского Алтая, представляли особую привлекательность для старообрядческих сообществ по причине своей уединённости. Здесь особенности взаимодействия русской и алтайской культур можно было наблюдать практически в чистом виде, как в положительных, так и в отрицательных аспектах.

Так, например, миссионеры Русской православной церкви настаивали на наличии между старообрядцами и алтайцами культурной розни, признаки которой они видели в том, что «раскольники» не едят вместе с алтайцами: не угощают их у себя, да и сами, бывая у них, не принимают от них угощения, «считая все ихнее нечистым, но нечистым не в отношении нечистоплотности и неопрятности их, а в отношении религиозного состояния их как язычников» $[9$, л. 2]. При этом позитивных моментов такого взаимодействия оказывалось все же больше; старожилы вспоминают, что старообрядцы жили с алтайцами дружно, несмотря на традиционное соблюдение ими «чашки». В этом стереотипе поведения - отказе давать чужим есть из своей посуды, - выражалось их стремление защититься об сообщения с иноверцами и тем самым соблюсти «чистоту»- не столько физическую, сколько духовную. Исходя из этих же соображений, они не давали свою посуду и русским «никонианам»; следовательно, причина состояла не в пренебрежительном отношении их к алтайцам как к язычникам, а в присущем их конфессиональной культуре стремлении избежать «мирщения».

Вместе с тем, Б. Г. Герасимов отмечает, что бухтарминские старообрядцы, которые всячески берегутся от замирщения и осквернения, при этом, однако, «спокойно едят на Алтайской ярмарке ... киргизскаго приготовления пельмени, нередко состряпанные даже из конины» [10, с. 12].

Важным признаком наличия процессов ассимиляции являлись браки кержаков Горного Алтая с представительницами коренного населения [8, с. 45]. Такие браки становились следствием ограниченности численности населения, обусловленной трудностями проникновения, освоения и проживания на этих территориях, отрезанных от окружающего мира. Преимущественно это была женитьба мужчинстарообрядцев на крещённых в старую веру алтайских девицах, а не наоборот: очевидно, причина состояла в том, что женщина легче входит в пространство чужой культуры, быстрее адаптируется к ней. В целом данная тенденция была вполне в рамках традиции русской колонизации Сибири, по крайней мере, до того момента, когда численность русского мужского и женского ее населения не уравнялась.

Но дело было не только в ограниченности человеческого ресурса: в замкнутых ландшафтах, подобных Уймонской долине, с постоянным составом населения выбор партнёра для вступления в брак представлял (и в некоторой степени представляет в настоящее время) определённую трудность. Как известно, православно-христианская традиция запрещает браки между родственниками до седьмого колена; старообрядцы старались придерживаться этого правила. Решения духовных соборов подтверждали запреты браков между родственниками, а наставники и священники получали право разводить их. Существует и такой немаловажный фактор, препятствующий заключению брака, как духовное родство, которое считается ещё ближе кровного.

Подобные принципы и запреты резко ограничивали число возможных вариантов для выбора невест. Поэтому в Уймонской долине в данном вопросе делались определённые послабления: считалось, что люди «выходят из родни» уже в четвёртом колене и, соответственно, считаются друг другу 
чужими, следовательно, могут вступать между собой в брачные отношения. Таких семей здесь и сегодня можно встретить немало; более того, существуют семьи, в которых супруги находятся в еще более близких степенях родства.

В этой ситуации возникала жизненно важная задача обновления генофонда - как говорят сами старожилы, время от времени необходимо было «прилить новую кровь», чем и объясняется периодически возникавшая «мода» на браки с алтайскими девицами. Считалось, что от таких браков рождаются красивые дети; действительно, здесь нередко встречаются люди, унаследовавшие антропологический облик от алтайских матерей, но по своему культурному наполнению являющиеся целиком и полностью русскими старообрядцами.

К такому родству старообрядцы относились столь же серьёзно, как и ко всякому другому; старожилы вспоминают случаи, когда кержаки в годы коллективизации предупреждали родственниковалтайцев об угрозе ареста, брали их в свои дома, прятали от репрессий [11].

Для представительниц коренного населения эти браки, с одной стороны, считались престижными и весьма желательными, с другой - означали для них полную смену культурной среды: другую одежду, другие занятия, обычаи, другую религию. В итоге в кержацких семьях они утрачивали свою этническую культуру и воспринимали старообрядческую, которую в настоящее время знают и помнят порой лучше самих старообрядцев.

Проблемой браков кержаков с алтайскими девушками являлось различие хозяйственнокультурных типов, и, следовательно, тех навыков и умений, которые необходимо было передать детям. Например, в семьях кочевников девочек обучали валять шерсть, в русских земледельческих хозяйствах учили обрабатывать лен. Известно, что в семьях русских сибиряков начинали приобщать детей к труду очень рано - с 5-6 лет: в этом возрасте девочкам вырезали прялку и учили прясть кудель, переходя затем к все более сложным рукодельям, так, чтобы к моменту достижения брачного возраста - 18 годам, они уже освоили все технологии, необходимые для ведения сложного крестьянского хозяйства. Таким образом, алтайским жёнам приходилось как можно скорее учиться новым для них видам хозяйственной деятельности.

Неудивительно поэтому, что в ряде случаев старообрядческие семьи брали на воспитание крещенных в их веру алтайских детей обоего пола, чтобы заранее обучить их навыкам крестьянского труда и затем, по мере их взросления, устроить их брак с кем-либо из собственных детей; таким образом, они избегали вырождения, физической и умственной деградации.

Переход алтайцев в старую веру осуществлялся и помимо браков: чаще всего он являлся следствием длительного соседства в одном населённом пункте, а также мог быть результатом миссионерского воздействия старообрядцев некоторых согласий. Миссионер Ининского отделения Алтайской духовной миссии, иеромонах Нифонт в своей записке, характеризуя деревню Ак-Кол, отмечает: «Население - почти исключительно старожилы-инородцы, весьма обруселые. Правда, есть несколько семей кержацкого толка, которые, несмотря на то, что калмыков считают погаными, всё-таки стараются вовлечь их в своё заблуждение» [12, л. 21].

Со своей стороны, старообрядцы заимствовали у кочевников отличное умение ездить верхом: по замечанию Н. М. Ядринцева, они «сумели сделаться прекрасными горными наездниками, не переставая быть земледельцами» [5, с. 618]. Располагая хорошими, купленными у кочевников, лошадьми, «бегунцами» (рысаками), к которым имели «особенную страсть», кержаки легко проезжали с вьюками или волокушами по горным, таёжным тропам и даже по бездорожью. В этом состояло их преимущество перед «российскими» переселенцами, которые плохо владели верховой ездой, поэтому могли продвигаться только тележными трактами, и к тому же слишком боялись «киргизов». Влияние кочевников отразилось и на внешнем облике старообрядцев - жителей пограничья; Е. Ф. Шмурло так описывает тип этих «полуудальцов, полуразбойников»: «Винтовка за плечами, нож за голенищем сапога - обычные его спутники» [13, с. 62].

Таким образом, в ходе колонизации горных районов Алтая старообрядцы объективно осуществляли цивилизаторскую миссию, расширяя пространство христианско-православной земледельческой культуры, вовлекая в неё обширные области и проживавшее на них местное автохтонное население. По мнению наблюдателей, культурное влияние старообрядцев на алтайцев было все же значительно более весомым, чем обратное: отмечалось, что, сближаясь с ними, они «мало-помалу обращают их совершенно в русских» [4, с. 41]. Вместе с тем является очевидным, что представители обеих цивилизаций показали здесь пример позитивного культурного взаимодействия, заимствуя друг у друга элементы хозяйства, мировоззрения и даже генофонда, которые считали необходимыми для экономического освоения территории, а порой и элементарного выживания в данных конкретных, весьма сложных природных и социальных условиях. 


\title{
Список литературы
}

1. Гребенщиков, Г. Д. Алтайская Русь: историко-этнографический очерк. - Барнаул : [б. и.], 1990. (Приложение к газете писателей Алтая «Прямая речь»). - 15 с. - Текст : непосредственный.

2. Михайлов, Г. П. Староверы как колонизаторы Уссурийского края. - Текст : непосредственный // Сибирские вопросы. - 1905. - № 1. - С. 247-258. - Текст : непосредственный.

3. Паллас, П. С. Путешествие по разным местам Российского государства / пер. с нем. Бунчуковый, Ф. Томанский. - Ч. 2. - Кн. 1: 1770 г.-Санкт-Петербург: Императорская Академия Наук, 1786. -614 с. Текст : непосредственный.

4. К обзору научной деятельности Западно-Сибирского географического отдела. - Текст : непосредственный // Юбилейный сборник Западно-Сибирского отдела Императорского русского географического общества. 1877-XXV-1902. - Омск, 1902. - С. 37-120.

5. Ядринцев, Н. М. Алтай и его инородческое царство. (Очерки путешествия по Алтаю). - Текст : непосредственный // Исторический вестник. - 1885. - Т. ХХ. - С. 607-644.

6. Ядринцев, Н. М. Раскольничьи общины на границе Китая. Земледелец - дипломат и воин. - Текст 6 непосредственный // Сибирский сборник. Приложение к «Восточному Обозрению» / под ред. Н. М. Ядринцева. - Санкт-Петербург : [б. и.], 1886. - Кн. 1. - С. 21-47.

7. Принтц, А. А. Каменьщики, ясачные крестьяне Бухтарминской волости Томской губернии и поездка в их селения и в Бухтарминский край в 1863 г. // Записки Императорского русского географического общества по общей географии. - Санкт-Петербург : Тип. Императорского акад. наук, 1867. - Т. 1. - С. 543-582.

8. Бухтарминские старообрядцы / под ред. С. И. Руденко.-Ленинград: Изд-во Академии наук СССР1930. - Вып. 17. - 464 с. - (Академия наук СССР : Материалы комиссии экспедиционных исследований; Вып. 17 : Серия Казахстанская). - Текст : непосредственный.

9. Государственный архив Алтайского края (ГААК). Ф. 164. Оп. 1. Д. 86.

10.Герасимов, Б.Г. В долине Бахтармы (Краткий исторически-географический очерк с 3 таблицами цифр). - Текст : непосредственный // Записки Семипалатинского подотдела Западно-Сибирского отдела Императорского русского географического общества. - Семипалатинск : Тип.-лит. Торг. Дома «П. Плещеев и К», 1911. - Вып. V. - С. 1-125.

11. Архив научно-исследовательской лаборатории «Культурное наследие Алтая» Алтайского государственного института культуры. Материалы историко-этнографической экспедиции. Усть-Коксинский р-н, 2013.

12. ГААК. Ф. 164. ОП. 1. Д. 151.

13. Шмурло, Е. Ф. Русские поселения за южным Алтайским хребтом. - Текст : непосредственный // Записки Западно-Сибирского отдела Императорского русского географического общества. - Омск : Тип. окружн. штаба, 1898. - Кн. XXV. - С. 1-64.

Irina $\boldsymbol{V}$. Kupriianova, Dr. of Historical Sciences, Associate Professor Altai State Institute of Culture (Barnaul, Russia) irinak-63@mail.ru

\section{RELATIONSHIPS BETWEEN RUSSIAN OLD BELIEVERS AND INDIGENOUS PEOPLES OF ALTAI AS A RESOURCE FOR COLONIZATION}

\begin{abstract}
The article considers ways of collaboration between Russian Old Believers and native population in the process of economic and cultural development of areas in Altai Mountains. Hard climate, a wish for isolation from settled territories and governmental centers made these contacts an almost one and only resource for surviving for Old Believers. One of the forms of interaction between these ethnic communities was establishing family relations among them; exchange of cultural information happened in an accelerated mode in such situation. As a result, Altaians were involved into a sphere of the Russian Orthodox Civilization.
\end{abstract}

Key words: Old Believers, Russian colonization of Gorny Altai (Altai Mountains) areas, contacts with nomads, ethnic and cultural assimilation, rebaptism of Altaians, spreading of agriculture, renewal of genetic pool. 